\title{
Stratospheric methane profiles from SCIAMACHY solar occultation measurements derived with onion peeling DOAS
}

\author{
S. Noël, K. Bramstedt, A. Rozanov, H. Bovensmann, and J. P. Burrows \\ Institute of Environmental Physics, University of Bremen, FB 1, P.O. Box 330440, 28334 Bremen, Germany \\ Received: 6 July 2011 - Published in Atmos. Meas. Tech. Discuss.: 29 July 2011 \\ Revised: 3 November 2011 - Accepted: 19 November 2011 - Published: 29 November 2011
}

\begin{abstract}
Stratospheric methane $\left(\mathrm{CH}_{4}\right)$ profiles have been derived from solar occultation measurements of the SCanning Imaging Absorption spectroMeter for Atmospheric CHartographY (SCIAMACHY) on ENVISAT with an updated version of the Onion Peeling DOAS (ONPD) method. The SCIAMACHY solar occultation measurements cover the latitudinal range between about $50^{\circ} \mathrm{N}$ and $70^{\circ} \mathrm{N}$. Currently, reasonable results are obtained between 20 and $40 \mathrm{~km}$ altitude. Comparisons with correlative ACE-FTS measurements show an average agreement within the expected accuracy of the ACE-FTS data of about $10 \%$. To demonstrate the capability of SCIAMACHY solar occultation measurements in the context of greenhouse gas monitoring, time series of stratospheric $\mathrm{CH}_{4}$ profiles covering the period from 2003 to 2010 have been generated. The SCIAMACHY $\mathrm{CH}_{4}$ profile solar occultation temporal series shows a strong seasonal cycle. This is attributed to the variations in both time and space of the retrieved data set. At lower altitudes, the observed temporal variations are explained by variations of the tropopause height. The temporal data set is also impacted by variations of the size and duration of the polar vortex in the northern hemisphere. The data set provides unique information about $\mathrm{CH}_{4}$ changes in the stratosphere at mid to high latitudes.
\end{abstract}

\section{Introduction}

Atmospheric methane $\left(\mathrm{CH}_{4}\right)$ is after water vapour and $\mathrm{CO}_{2}$ the most important greenhouse gas. $\mathrm{CH}_{4}$ is released into the troposphere by both natural processes and anthropogenic activity. Because of its long tropospheric chemical lifetime of

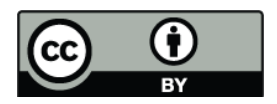

Correspondence to: S. Noël (stefan.noel@iup.physik.uni-bremen.de) about 8 to $10 \mathrm{yr}, \mathrm{CH}_{4}$ can be transported into the stratosphere where it is oxidised. The latter is initiated primarily by reactions with $\mathrm{OH}, \mathrm{O}\left({ }^{1} \mathrm{D}\right)$ and also $\mathrm{Cl}$ atoms. Thereby $\mathrm{CH}_{4}$ is the major source of water vapour and $\mathrm{HCl}$. As a result $\mathrm{CH}_{4}$ plays a significant role in stratospheric chemistry. In the lower stratosphere these loss reactions are however sufficiently slow that $\mathrm{CH}_{4}$ can be also used as a dynamical tracer at these altitudes (see e.g. De Mazière et al., 2008). The coupling between stratospheric $\mathrm{CH}_{4}$ and water vapour (and their trends) is of relevance for atmospheric chemistry and climate change (see e.g. Rohs et al., 2006).

Several space-borne instruments provided stratospheric $\mathrm{CH}_{4}$ data in the past, among these the Atmospheric Trace Molecule Spectroscopy experiment (ATMOS; Gunson et al., 1990), the Improved Stratospheric and Mesospheric Sounder (ISAMS; Taylor et al., 1993; Remedios et al., 1996), the Cryogenic Limb Array Etalon Spectrometer (CLAES; Roche et al., 1996) and the Halogen Occultation Experiment (HALOE; Russell et al., 1993). All these instrument are no longer operating. Currently, $\mathrm{CH}_{4}$ profiles are e.g. provided by the Atmospheric Chemistry Experiment Fourier Transform Spectrometer (ACE-FTS) on SCISAT (Bernath et al., 2005), launched in 2003, and the Michelson Interferometer for Passive Atmospheric Sounding (MIPAS; Fischer et al., 2008; Payan et al., 2009) on ESA's environmental satellite ENVISAT.

The SCanning Imaging Absorption spectroMeter for Atmospheric CHartographY (SCIAMACHY; Bovensmann et al., 1999) is also part of the atmospheric chemistry payload of ENVISAT, which was launched in 2002. Originally the lifetime of ENVISAT was guaranteed by its constructors to be $5 \mathrm{yr}$ and the concept was to have a series of ENVISAT satellites to produce a long term data record. However, ENVISAT and its instruments, including SCIAMACHY, are still

Published by Copernicus Publications on behalf of the European Geosciences Union. 
operational. An extension of the ENVISAT mission to at least 2014 and hopefully beyond is planned.

SCIAMACHY makes measurements of the electromagnetic radiation leaving the top of the atmosphere in nadir, limb and both solar and lunar viewing geometries. Appropriate mathematical inversion of these data yields the amounts and distributions of atmospheric trace gases, cloud and aerosol parameters.

In this manuscript the retrievals of $\mathrm{CH}_{4}$ from solar occultation measurements, which are performed every orbit at Northern latitudes between about $50^{\circ}$ and $70^{\circ}$, are described and analysed. Although these measurements are limited in latitude range the signal-to-noise ratio of the occultation measurements is high (see e.g. Noël et al., 1998) and they are less sensitive to calibration issues, yielding high precision retrieved data products. The long duration of SCIAMACHY of already now more than $9 \mathrm{yr}$ provides a unique set of decadal data about the atmospheric composition at mid to high latitudes in the Northern Hemisphere.

In this manuscript results from a new retrieval method, used to derive stratospheric profiles of methane $\left(\mathrm{CH}_{4}\right)$ from SCIAMACHY solar occultation measurements, are presented. The retrieval method is based on a combination of an onion peeling approach (see e.g. Russell and Drayson, 1972) with a weighting function DOAS (Differential Optical Absorption Spectroscopy) fit (see e.g. Coldewey-Egbers et al., 2005). This is an extension of the Onion Peeling DOAS (ONPD) method which has already been successfully applied to water vapour (Noël et al., 2010). The main differences of the present method compared to the method described in Noël et al. (2010) are the use of weighting functions instead of optical depths and the different (a-posteriori) saturation correction (as described in the following sections). A discussion on the advantages and disadvantages of the ONPD method in comparison to other strategies like optimal estimation is given in Noël et al. (2010).

Here, we present first retrieval results for stratospheric $\mathrm{CH}_{4}$ profiles from SCIAMACHY and compare them with correlative data from ACE-FTS. Furthermore, time series of stratospheric methane profiles (based on $8 \mathrm{yr}$ of SCIAMACHY solar occultation data) are presented, showing the capability of SCIAMACHY solar occultation measurements in the context of greenhouse gas monitoring.

The manuscript is structured as follows: in Sect. 2 the retrieval method is described. Section 3 contains the results of the comparison with ACE-FTS. An analysis of SCIAMACHY stratospheric $\mathrm{CH}_{4}$ time series for the time interval August 2002 to December 2010 is given in Sect. 4. The results are then summarised in the conclusions (Sect. 5).

\section{Retrieval method}

\subsection{General approach}

The Onion Peeling DOAS (ONPD) algorithm is based on a weighting function DOAS (Differential Optical Absorption Spectroscopy) fitting approach (see e.g. Coldewey-Egbers et al., 2005) which is combined with an onion peeling approach (see e.g. Russell and Drayson, 1972).

For the onion peeling the atmosphere is divided into layers. The retrieval starts at the top layer and then propagates downwards, taking into account the results of the upper layers. Weighting functions are used to describe the change of the measured signal as a function of the absorber amount (or other atmospheric parameters, like temperature) in each layer.

Let $c_{i, k}$ be the atmospheric parameter associated to the absorption features (e.g. the number density of absorber $k$ ) in atmospheric layer $i$. With $I_{j}$ we denote the measured radiance in solar occultation for an instrument looking at tangent altitude $j . I_{0}$ is the corresponding radiance at a high reference altitude where atmospheric absorption can be neglected. In the present case, $I_{0}$ is taken from a measurement at about $200 \mathrm{~km}$ tangent altitude. By analogy to the weighting function DOAS approach, the logarithm of the solar transmittance $I_{j} / I_{0}$ is then given by:

$\ln \left(\frac{I_{j}}{I_{0}}\right)=P_{j}+\ln \left(\frac{I_{j, \text { ref }}}{I_{0, \text { ref }}}\right)+\sum_{k=1}^{N_{\text {abs }}} \sum_{i=j}^{N_{\text {layer }}} \alpha_{i j, k} a_{i, k}$

The quantities $I_{j, \text { ref }}$ and $I_{0, \text { ref }}$ are the corresponding radiances for the same tangent altitudes calculated for a reference scenario (i.e. for a reference set of parameters $c_{i, k, \text { ref }}$ ) with a radiative transfer program (SCIATRAN V2.2 in transmission mode; Rozanov et al., 2005).

The quantity $\alpha_{i j, k}$ describes the change of the (logarithmic) transmittance when changing the atmospheric parame-

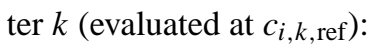

$\alpha_{i j, k}:=\left.\frac{\partial \ln \left(I_{j} / I_{0}\right)}{\partial c_{i, k}}\right|_{c_{i, k, \text { ref }}}$

The $\alpha_{i j, k}$ are therefore equivalent to relative weighting functions. They are determined by radiative transfer calculations with SCIATRAN 2.2. A main advantage of the weighting function DOAS method is, that dependencies on pressure and temperature can be handled in a similar way as for absorbers, i.e. via corresponding weighting functions. Therefore, $c$ may in principle be any parameter, which influences the measured (or simulated) radiance, e.g. a number density of an atmospheric constituent, pressure or temperature.

$a_{i, k}$ is a scalar factor which is defined as the relative change of $c_{i, k}$, i.e.:

$a_{i, k}:=\frac{\Delta c_{i, k}}{c_{i, k, \text { ref }}}=\frac{c_{i, k}-c_{i, k, \text { ref }}}{c_{i, k, \text { ref }}}$ 
$P_{j}$ is a low-order polynomial by which - as it is typical for DOAS methods - differences between simulated and real broadband absorption features are handled. For solar occultation measurements at the wavelength of the $\mathrm{CH}_{4}$ absorption the signal is dominated by the transmitted solar radiance; scattering processes can be neglected to a first approximation. Therefore the polynomial here mainly compensates uncertainties in the radiometric calibration.

The retrieval starts at the top of the atmosphere $\left(j=N_{\text {layer }}\right)$ and then propagates downwards. For each tangent altitude the coefficients of $P_{j}$ and the corresponding $a_{j, k}$ are determined via a non-linear least squares fit. Furthermore, a (wavelength independent) spectral shift is fitted to account for uncertainties in the spectral calibration. Note that for each atmospheric parameter $k$ only one $a_{j, k}$ needs to be determined in one step as the values for altitudes $i>j$ have been determined before.

Finally, the atmospheric parameter $c_{j, k}$ (e.g. the number density of the absorber $k$ at altitude $j$ ) is then given by (see Eq. 3):

$c_{j, k}=\left(1+a_{j, k}\right) c_{j, k, \text { ref }}$

As mentioned above, $c_{j, k, \text { ref }}$ is the reference value for $c_{j, k}$ as used in the radiative transfer calculations from which the simulated transmissions $I_{j \text {, ref }} / I_{0 \text {,ref }}$ as well as the $\alpha$ 's have been determined.

With the ONPD method it is in principle possible to derive profiles for all kind of atmospheric constituents, which can be handled by the radiative transfer model, provided sufficient information on these constituents is contained in the measured spectra. The actual constituents which need to be considered depend on the selected fit window. In case of methane retrieval, a fit window of 1559-1671 nm has been selected, and the considered quantities are $\mathrm{CH}_{4}$ and $\mathrm{CO}_{2}$ concentrations and temperature.

\subsection{Radiative transfer data base}

The ONPD method uses a pre-calculated data base of reference transmission spectra $\left(I_{j, \text { ref }} / I_{0, \text { ref }}\right)$, and weighting functions $\left(\alpha_{i j, k}\right)$. These quantities are determined using the SCIATRAN radiative transfer model for fixed atmospheric conditions, considering also refraction effects. In the present case, pressure and temperature profiles have been (arbitrarily) taken from ECMWF (European Centre for Medium Range Weather Forecasts) data for 26 July 2005, 00:00 UTC, $51^{\circ} \mathrm{N},-49.5^{\circ} \mathrm{E}$. For $\mathrm{CO}_{2}$ a constant volume mixing ratio (VMR) of 380 ppmv has been assumed. The $\mathrm{CH}_{4}$ profile is taken from the 1976 US standard atmosphere. The actual choice of these reference conditions is of minor importance for the retrieval results, as deviations between real and simulated conditions are handled by the weighting functions. The underlying assumption, however, is a linear relationship between absorber amount and measured absorption features, i.e. it is assumed that the weighting functions do not depend on the actual absorber amount. In a first order approximation this is true, but especially for strong line absorbers like $\mathrm{CO}_{2}$ and $\mathrm{CH}_{4}$ non-linearities play a (lower order) role. These are handled by additional corrections applied after the retrieval, as explained below.

The reference radiance spectra $I_{0, \text { ref }}$ and $I_{\text {ref }}$ have been calculated based on spectrally high resolved simulated SCIATRAN transmissions and a solar reference spectrum determined from an empirical solar line list provided by G. Toon, NASA JPL. The ratio $I_{j \text {,ref }} / I_{0 \text {, ref }}$ is determined after convolution of the radiance spectra.

The high-resolution spectral radiances are convolved with the SCIAMACHY spectral response function (or slit function), which is assumed to be a Gaussian with full width at half maximum (FWHM) of $1.15 \mathrm{~nm}$. This FWHM has been determined as a best fit value for the occultation retrieval, i.e. it is the FWHM, which results in the smallest errors of the fitted parameters. Note that the derived FWHM is smaller than the FWHM used in e.g. nadir retrievals (which is about $1.3 \mathrm{~nm}$ ); this is because the solar occultation measurements are performed with a smaller aperture, which alters the slit function.

\subsection{Application to SCIAMACHY methane retrieval}

The altitude grid used in the retrieval extends from 0 to $50 \mathrm{~km}$ in $1 \mathrm{~km}$ steps. The retrieval is performed for all altitudes starting at $50 \mathrm{~km}$ until $15 \mathrm{~km}$, but for methane useful results are only achieved between 20 and $40 \mathrm{~km}$ due to tropospheric effects at lower altitudes and too much noise at higher altitudes. An extension of the retrieval to lower altitudes will be subject to further studies.

SCIAMACHY performs solar occultation measurements by regular scans over the solar disk while following the rising sun. Note that due to the orbital motion of the satellite SCIAMACHY sees a sunrise, but the local time at the tangent point corresponds to sunset. One upward or downward scan takes $2 \mathrm{~s}$. The integration time for the SCIAMACHY measurements depends on wavelength. In the $\mathrm{CH}_{4}$ fit window 16 readouts are taken during one scan, pointing at different regions of the sun. A subset of these SCIAMACHY data has been selected for the retrieval, namely only upward scans and four readouts close to the solar centre. This results in a typical vertical sampling of about $3 \mathrm{~km}$. The transmission is computed for tangent altitudes below $60 \mathrm{~km}$ by division of the spectrum obtained at a certain tangent height to a corresponding spectrum measured at around $200 \mathrm{~km}$ tangent height, considering matching relative positions on the sun. Dead/bad detector pixels have been removed using a manually determined mask. To avoid impacts on $\mathrm{CH}_{4}$ time series the same dead/bad pixel mask has been used for all data.

Before the retrieval the (logarithms of the) transmissions measured by SCIAMACHY are (linearly) interpolated to the retrieval grid; this interpolation is required by the onion peeling method. 

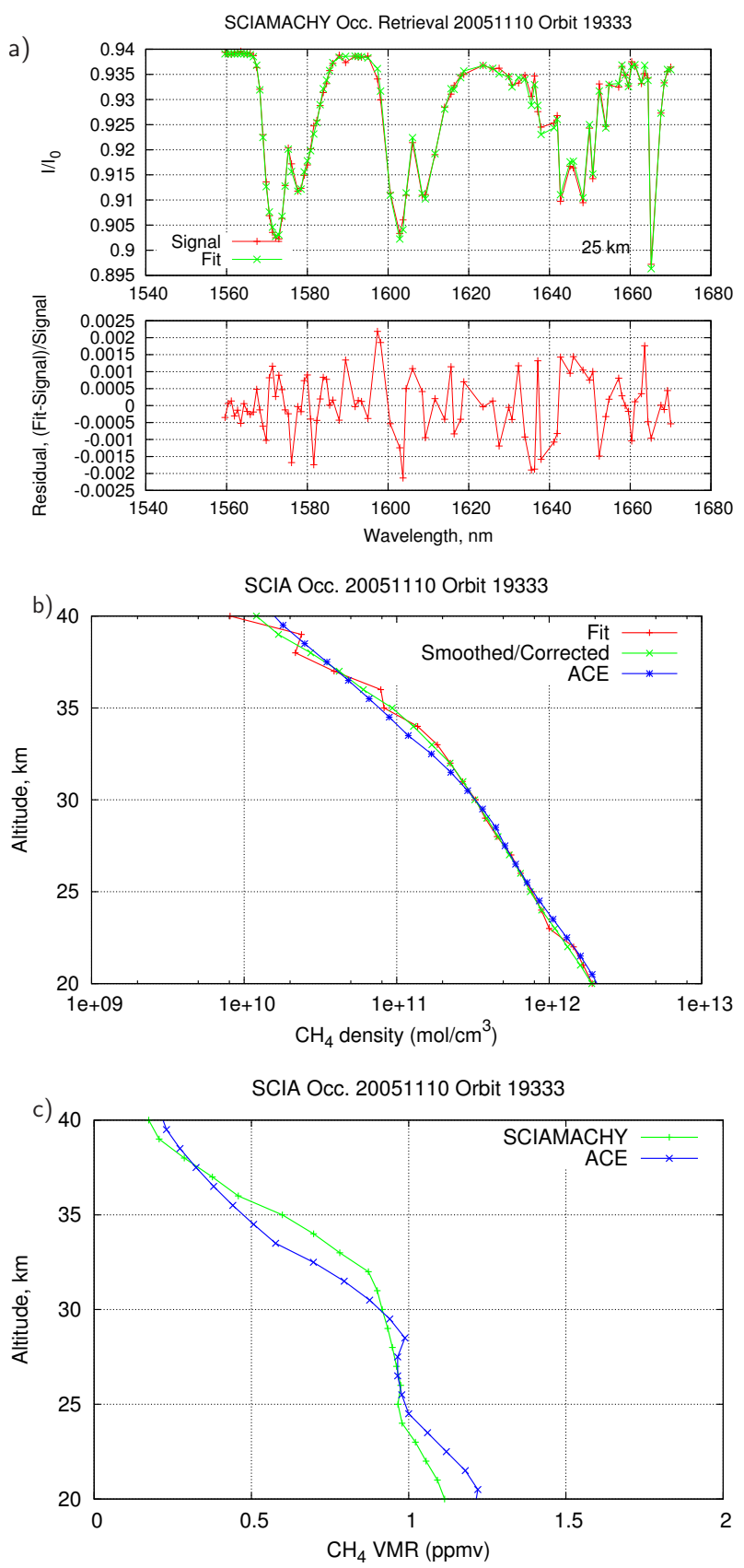

Fig. 1. Example for a $\mathrm{CH}_{4}$ fit. (a) Measured and fitted spectra at $25 \mathrm{~km}$ tangent altitude (top) and resulting residual (bottom). (b) Derived number density profile: uncorrected (red) and after all corrections (green); blue: corresponding ACE-FTS profile. (c) Corresponding $\mathrm{CH}_{4}$ VMR profiles.

Figure 1 shows in sub-panel (a) an example for a $\mathrm{CH}_{4}$ fit at $25 \mathrm{~km}$ and the corresponding residual. The two strong absorption features below about $1620 \mathrm{~nm}$ are due to $\mathrm{CO}_{2}$ absorption whereas the structures above $1620 \mathrm{~nm}$ are dominated by $\mathrm{CH}_{4}$ absorption with some underlying $\mathrm{CO}_{2}$. The two $\mathrm{CO}_{2}$ absorption features below $1620 \mathrm{~nm}$ are also fitted and have been mainly included to constrain the underlying $\mathrm{CO}_{2}$ absorption in the spectral range of the $\mathrm{CH}_{4}$ absorption. This results in a reduced error of the retrieved $\mathrm{CH}_{4}$ concentrations. As can be seen, the agreement between measurement and fit is quite well; maximum residuals are about $0.3 \%$ at this altitude. Note that between 20 and $40 \mathrm{~km}$ the resulting residuals are very similar; they increase a bit towards lower altitudes but are still of comparable magnitude.

After the retrieval, some additional corrections are applied which are described in Sect. 2.4. Sub-panel (b) of Fig. 1 shows an example for a $\mathrm{CH}_{4}$ number density profile derived directly from the fit (red curve) and the corresponding profile after application of all corrections including vertical smoothing (green curve). For illustration, a profile derived from collocated ACE-FTS measurements is also plotted (blue curve); for this purpose the original ACE-FTS VMRs have been converted to number densities using pressure and temperature data also provided by ACE-FTS.

Finally, VMRs are derived from retrieved SCIAMACHY $\mathrm{CH}_{4}$ number densities using pressure and temperature information obtained from collocated ECMWF data. In future retrievals pressure and temperature information could also be obtained directly from SCIAMACHY retrievals, e.g. by using observations of $\mathrm{O}_{2}$. The resulting profiles for the example case are shown in sub-panel (c) of Fig. 1, together with a corresponding collocated ACE-FTS VMR profile.

As can be seen, SCIAMACHY $\mathrm{CH}_{4}$ VMRs are somewhat higher than the ACE-FTS data between about $30 \mathrm{~km}$ and $37 \mathrm{~km}$ and lower above and below. This is in general confirmed by an extended comparison involving a larger set of collocated data which is described in Sect. 3 below.

For the results presented in this paper only retrieved $\mathrm{CH}_{4}$ VMRs with an absolute error (derived from the fit residuals as described in Sect. 2.5) smaller than 1 ppmv between 20 and $40 \mathrm{~km}$ are considered. This criterium is used to identify and remove data resulting from poor fits. However, only two profiles of more than 33000 for the whole time interval until end of 2010 considered here are affected by this.

\subsection{Corrections}

\subsubsection{Vertical smoothing}

The original radiative transfer calculations for the reference data base as well as the retrieval are performed on a $1 \mathrm{~km}$ altitude grid. However, the vertical resolution of the measurements is limited by the vertical size of the SCIAMACHY field of view $\left(0.045^{\circ}\right.$, corresponding to about $2.6 \mathrm{~km}$ at the tangent point). Furthermore, the vertical atmospheric range seen by SCIAMACHY during one readout is extended by the vertical scan over the sun (covering about $2.4 \mathrm{~km}$ ) and the movement of the rising sun (about $0.4 \mathrm{~km}$ during one readout). During upward scan, all these contributions add up to a total vertical range of about $4.1 \mathrm{~km}$ covered by one 

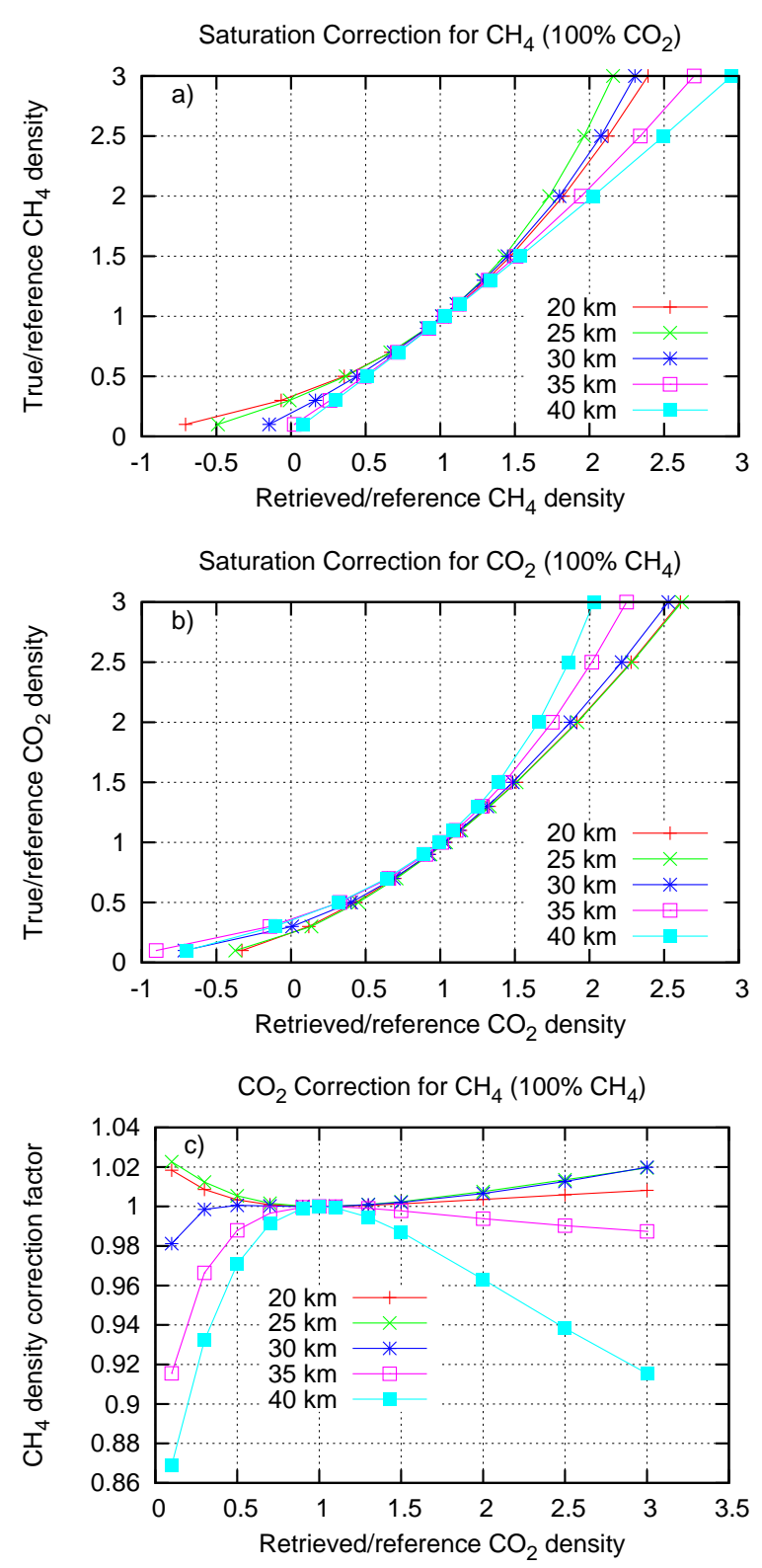

Fig. 2. (a) Saturation correction for $\mathrm{CH}_{4}$ as function of altitude and (smoothed) $\mathrm{CH}_{4}$ concentration. (b) Saturation correction for $\mathrm{CO}_{2}$ as function of altitude and (smoothed) $\mathrm{CO}_{2}$ concentration. (c) $\mathrm{CO}_{2}$ correction factor for $\mathrm{CH}_{4}$ as function of altitude and (saturation corrected) $\mathrm{CO}_{2}$ concentration.

SCIAMACHY measurement ${ }^{1}$. To consider this, the retrieved profiles are vertically smoothed using a boxcar of width $4.1 \mathrm{~km}$. This accounts for the limited vertical resolution of the measurement and also removes artificial oscillations in the profiles introduced by the retrieval.

\footnotetext{
${ }^{1}$ Note that due to the scan only half of the field of view size contributes to this number.
}

\subsubsection{Saturation correction}

Absorption features of $\mathrm{CH}_{4}$ and $\mathrm{CO}_{2}$ (and also water vapour) are highly structured. The spectral resolution of the SCIAMACHY instrument is not sufficient to resolve the strongly varying individual absorption lines in the region around $1.6 \mu \mathrm{m}$. The measured signal is a convolution of saturated and non-saturated lines. This results in a non-linear relationship between absorber amount and absorption depth (usually referred to as saturation effect). This means that the weighting function depends on the linearisation point, i.e. the absorber concentration.

Furthermore, as mentioned in the previous subsection, the vertical resolution of the SCIAMACHY measurements (about $4.1 \mathrm{~km})$ is lower than the retrieval grid size $(1 \mathrm{~km})$. This is not considered in the radiative transfer calculations used to determine the weighting functions and reference spectra.

To account for these effects, a correction is applied which depends on tangent altitude and the (retrieved) absorber density. This correction is called here "saturation correction", although it in facts corrects for more than just saturation effects.

The saturation correction is determined by application of the retrieval to a set of simulated data for different absorber amounts, realised by scaling the input profiles of the corresponding absorber for the radiative transfer calculations by a given (altitude independent) factor. In the present case 12 scaling factors between $10 \%$ and $300 \%$ have been used to cover the spatial and temporal variability of $\mathrm{CH}_{4}$ number densities. Furthermore, the simulated input spectra are sampled to the (in this fit window) typical SCIAMACHY spectral sampling of about $0.8 \mathrm{~nm}$ and vertically smoothed by a $4.1 \mathrm{~km}$ boxcar to account for the limited vertical resolution.

The functional dependence between the retrieved and the true $\mathrm{CH}_{4}$ density is derived for each altitude. Examples for five altitudes are shown in sub-panel (a) of Fig. 2. The correction is then performed by interpolation of the 'true' number density to the retrieved $\mathrm{CH}_{4}$ number density (after smoothing) at a given altitude.

As can be seen from Fig. 2a, the correction is typically larger at lower altitudes and small for $\mathrm{CH}_{4}$ densities close to the reference density. However, for $\mathrm{CH}_{4}$ number densities deviating larger than about $\pm 50 \%$ from the reference the effect increases and would typically result in an under-estimation of the retrieved concentrations, if not corrected for.

\subsection{3 $\mathrm{CO}_{2}$ correction}

Unfortunately, the saturation correction for $\mathrm{CH}_{4}$ is not only a function of the $\mathrm{CH}_{4}$ concentrations only, but also depends slightly on the $\mathrm{CO}_{2}$ number density. Although the $\mathrm{CO}_{2}$ VMRs are rather constant in both time and altitude as 

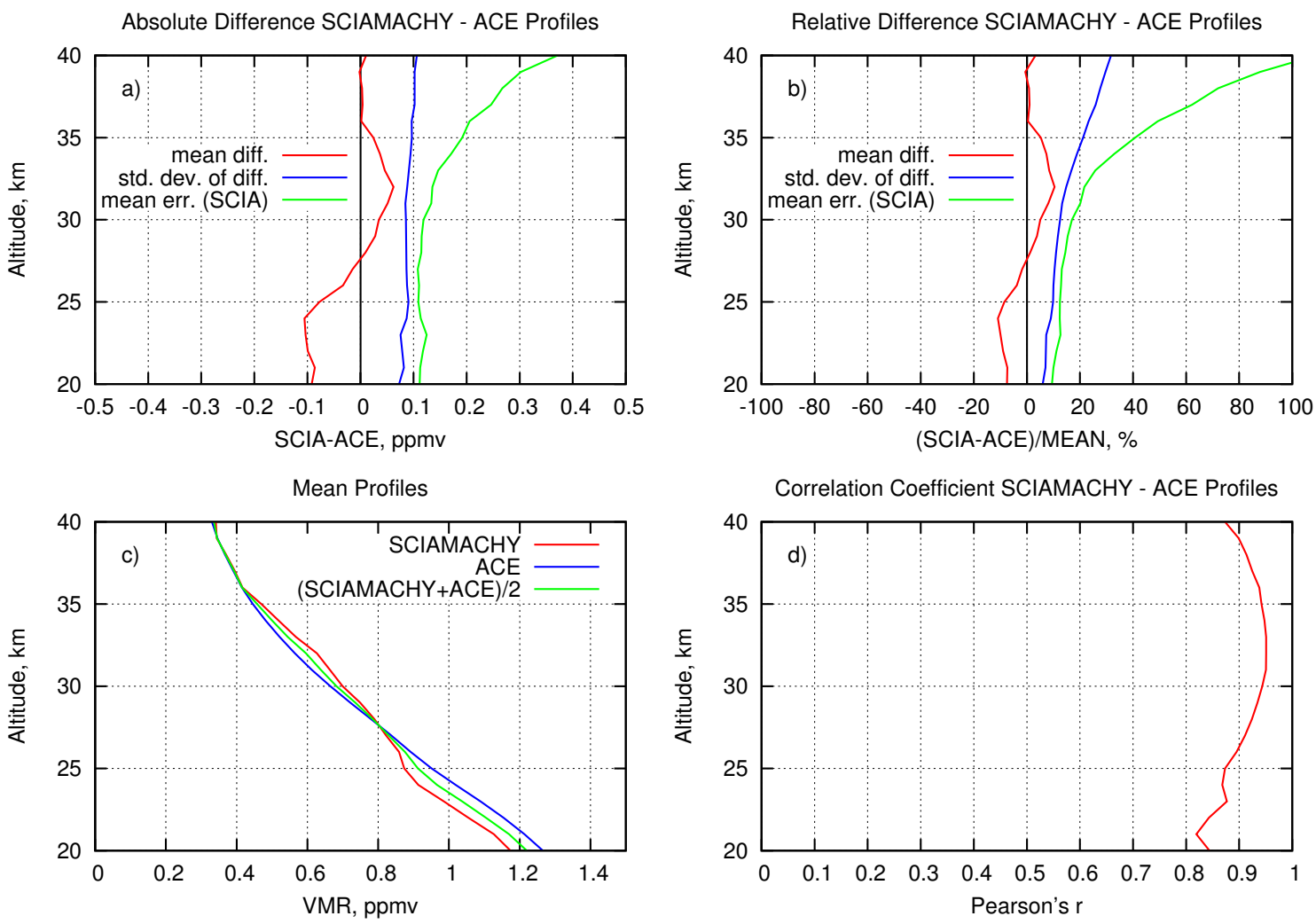

Fig. 3. Comparison of retrieved SCIAMACHY methane profiles (ONPD V3.3.6) with ACE-FTS data (V2.2). (a) Mean absolute difference (red) and its standard deviation (blue); mean absolute error of SCIAMACHY data (green). (b) Mean relative difference (red) and its standard deviation (blue); mean relative error of SCIAMACHY data (green). (c) Mean profiles (red: SCIAMACHY, blue: ACE-FTS, green: average of both). (d) Correlation between SCIAMACHY and ACE-FTS data.

compared to that of $\mathrm{CH}_{4}$, the $\mathrm{CO}_{2}$ number densities vary with temperature and pressure and thus with season.

Overall, an additional $\mathrm{CO}_{2}$ correction is required for $\mathrm{CH}_{4}$. The $\mathrm{CO}_{2}$ correction is a multiplicative factor which depends on tangent altitude and the retrieved $\mathrm{CO}_{2}$ density. It is determined in a similar way as the $\mathrm{CH}_{4}$ saturation correction by application of the retrieval to a set of simulated data, but now with constant $(100 \%) \mathrm{CH}_{4}$ but varying (scaled) $\mathrm{CO}_{2}$ profiles. The $\mathrm{CO}_{2}$ correction factor is defined as the ratio of the true to the retrieved $\mathrm{CH}_{4}$ number density. Note that the impact of variable $\mathrm{CH}_{4}$ on the retrieved $\mathrm{CO}_{2}$ is very low, usually much less than $1-2 \%$, which is uncritical for the $\mathrm{CO}_{2}$ correction.

The $\mathrm{CO}_{2}$ correction is applied to the (saturation corrected) $\mathrm{CH}_{4}$ profiles and depends on altitude and the retrieved $\mathrm{CO}_{2}$ number density. Therefore it is also necessary to compute a saturation correction for $\mathrm{CO}_{2}$. This is done in a similar way as for $\mathrm{CH}_{4}$, using the scaled $\mathrm{CO}_{2}$ profiles mentioned above. The result is shown in sub-panel (b) of Fig. 2. The shape of the derived $\mathrm{CO}_{2}$ saturation correction is very similar to the $\mathrm{CH}_{4}$ case. However, for $\mathrm{CO}_{2}$ the corrections are typically larger at higher altitudes.
The derived $\mathrm{CO}_{2}$ correction (Fig. 2c) is based on the same set of scaling factors as used for $\mathrm{CH}_{4}$; actual $\mathrm{CO}_{2}$ correction factors are then obtained by interpolation to the retrieved (saturation corrected) $\mathrm{CO}_{2}$ number density. However, for the spatial and temporal range covered by the SCIAMACHY solar occultation measurements the derived variability of the $\mathrm{CO}_{2}$ number densities is much smaller than for $\mathrm{CH}_{4}$ (only about $50 \%$ ). Therefore, the actually required $\mathrm{CO}_{2}$ correction factor is usually only a few percent.

\subsection{Errors of the SCIAMACHY methane product}

The error estimated for the SCIAMACHY methane concentrations as used in the present paper is essentially determined from the root mean square (RMS) of the fit residuals divided by the corresponding weighting function (which converts the spectral error into a trace gas error). As mentioned above, the fit residual - and therefore also the RMS - is rather constant with altitude, but the weighting functions significantly decrease with altitude. As a consequence, the estimated errors typically increase with altitude. It is expected that the additional corrections applied to the data after the retrieval (as described in Sect. 2.4) reduce the error on the data product. 
a)
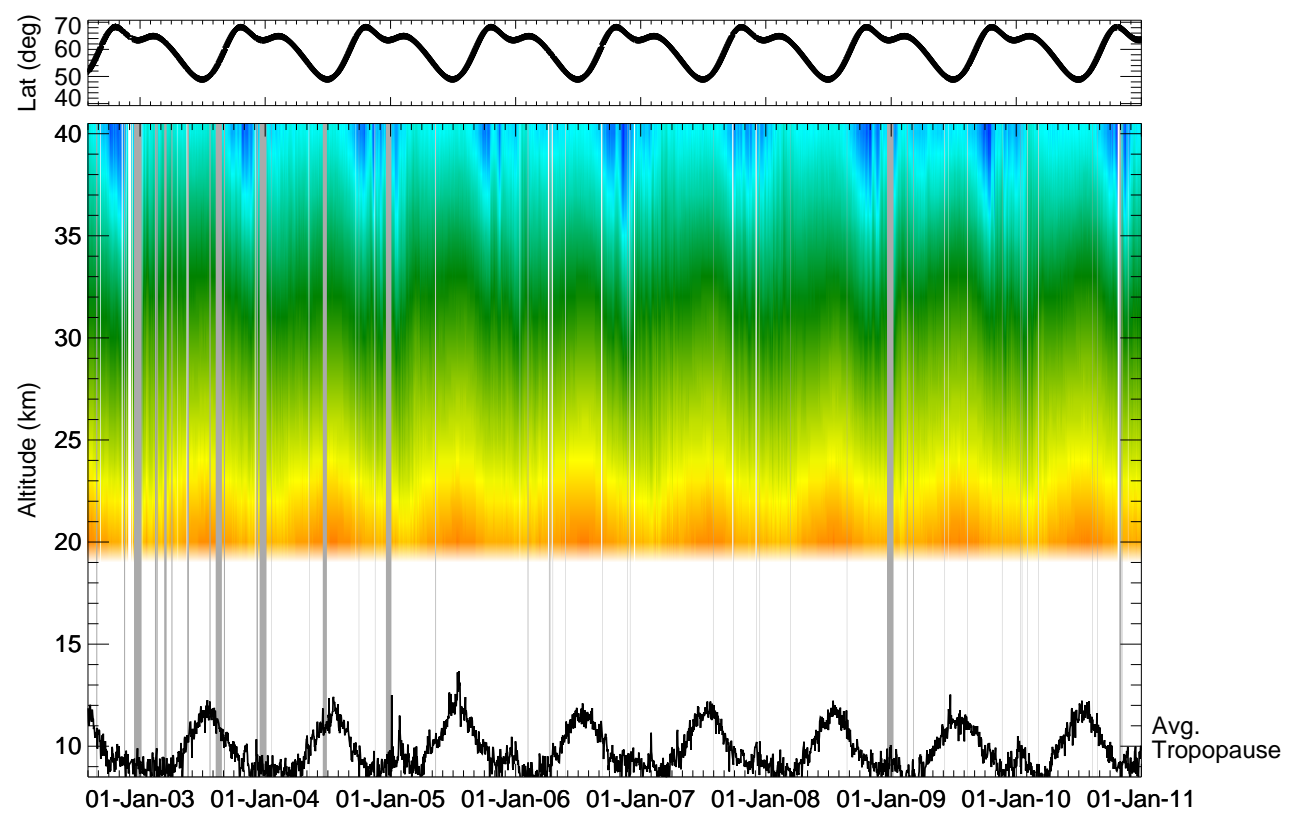

$\mathrm{CH}_{4}$ Density (molecules $/ \mathrm{cm}^{3}$ )

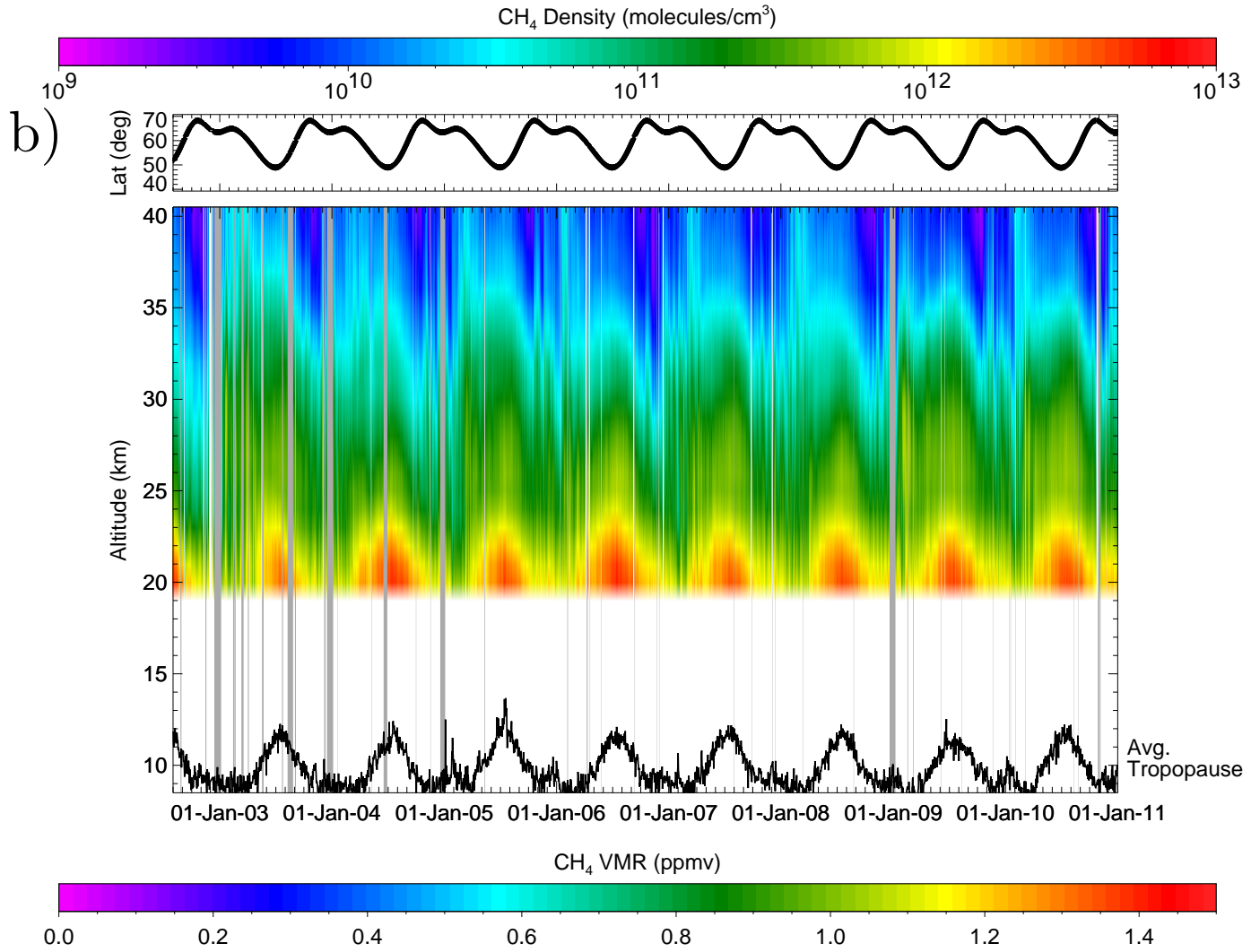

Fig. 4. Time series of daily averaged $\mathrm{CH}_{4}$ profiles August 2002 - December 2010. (a) Retrieved number densities. (b) Volume mixing ratios (VMRs) derived from combination with ECMWF pressure and temperature data. In both sub-figures the latitudinal range covered by the SCIAMACHY measurements is indicated on the top. The black curve on the bottom shows the average tropopause height, derived from collocated ECMWF data. The vertical grey bars mask out periods of reduced SCIAMACHY data quality (e.g. due to instrument switch-offs or decontamination periods). 
However, the impact of these corrections on the errors is difficult to be quantified. For example, the smoothing procedure changes the vertical resolution of the data, and therefore also the weighting functions. On the other hand, the vertical sampling of the original measurements is only about $3 \mathrm{~km}$, whereas the retrieval is performed on a $1 \mathrm{~km}$ grid using interpolated measurements. The estimation of the impact of the additional saturation correction and $\mathrm{CO}_{2}$ correction is even more difficult, as these also affect potential systematic errors. Therefore, the a-posteriori corrections have explicitly not been considered in the error estimates, which results in an over-estimation of the estimated error. A discussion of other potential systematic error sources (e.g. spectroscopy or pointing uncertainties) can be found in Noël et al. (2010).

\section{Preliminary validation}

The retrieved $\mathrm{CH}_{4}$ profiles have been compared with collocated $\mathrm{CH}_{4}$ profiles derived from the Atmospheric Chemistry Experiment Fourier Transform Spectrometer (ACE-FTS). ACE-FTS is the main payload of the Canadian SCISAT satellite (Bernath et al., 2005), launched in August 2003. The ACE-FTS instrument performs solar occultation measurements in the infrared wavelength range (2.2 to $13.3 \mu \mathrm{m})$. It provides altitude profiles for temperature, pressure and VMRs of various atmospheric molecules, including $\mathrm{CH}_{4}$ as a key species.

In this manuscript we compare with ACE-FTS $\mathrm{CH}_{4}$ data V2.2. These data have been intensively validated by various comparisons with ground-based, balloon-borne and satellitebased measurements (see De Mazière et al., 2008), resulting in an estimated accuracy of the $\mathrm{CH}_{4}$ profiles within about $10 \%$ in the upper troposphere and lower stratosphere and within $25 \%$ in the middle and higher stratosphere and the lower thermosphere. Recently, an updated ACE-FTS data set (V3) has been made available, but no validation results have been published yet; therefore we currently restrict our analysis to the V2.2 data.

About 900 collocations between SCIAMACHY and ACEFTS are found assuming a maximum tangent point distance of $500 \mathrm{~km}$ and measurements at the same day during local sunset. For these collocations the following statistical quantities are determined:

- The mean and standard deviation of the difference between SCIAMACHY and ACE-FTS VMRs, in VMR units (shown in Fig. 3a).

- The estimated mean error of the SCIAMACHY VMRs, i.e. the averaged error (as described in Sect. 2.5) of the single profiles (green line in Fig. 3a).

- The mean SCIAMACHY and ACE-FTS profiles for the set of collocated data and their difference (see Fig. 3c).
- The mean relative deviations between SCIAMACHY and ACE-FTS and the corresponding standard deviations (Fig. 3b, red and blue lines). These have been obtained by dividing the absolute values from Fig. 3a by the arithmetic mean of the average SCIAMACHY and ACE-FTS profiles given in Fig. 3c.

- The estimated mean relative error of the SCIAMACHY VMRs (green line in Fig. 3b), obtained by dividing the absolute errors by the average SCIAMACHY profile. This error can be interpreted as a typical error of a single SCIAMACHY $\mathrm{CH}_{4}$ profile.

- The correlation coefficient (Pearson's r) between the SCIAMACHY and the ACE-FTS data, which is shown in Fig. 3d.

As shown in Fig. 3, SCIAMACHY and ACE-FTS $\mathrm{CH}_{4}$ VMRs agree within about $\pm 10 \%$, which is in line with the expected accuracy of the ACE-FTS V2.2 data product of about $10 \%$. Below about $28 \mathrm{~km}$ SCIAMACHY VMRs are typically lower than the corresponding ACE-FTS values (up to 0.1 ppmv below $25 \mathrm{~km}$ ); between 28 and $35 \mathrm{~km} \mathrm{SCIA-}$ MACHY VMRs are larger that ACE-FTS VMRs; above they agree very well. The estimated mean error of the SCIAMACHY $\mathrm{CH}_{4}$ profiles lies between 10 and $20 \%$ below $30 \mathrm{~km}$ and strongly increases for higher altitudes, reaching more than $100 \%$ at $40 \mathrm{~km}$. The agreement with ACE-FTS at these altitudes is however still good. This is probably because the given SCIAMACHY errors are under-estimated, as described in Sect. 2.5.

The correlation between the SCIAMACHY and ACE-FTS $\mathrm{CH}_{4}$ VMRs is always larger than 0.8 ; between 30 and $35 \mathrm{~km}$ it reaches 0.95 . This indicates that $\mathrm{CH}_{4}$ variations seen by ACE-FTS are also seen by SCIAMACHY.

\section{Time series}

Up to now, the ONPD method has been applied to all SCIAMACHY solar occultation measurements from August 2002 until end of 2010. Up to $13 \mathrm{CH}_{4}$ profiles are obtained per day at almost the same latitude but different longitudes. Based on these data, daily averages are computed which are shown in Fig. 4a for number densities and Fig. 4b for VMRs. Because of the different longitudes covered during one day these are in fact also zonal averages. Data from times of reduced instrument performance, like instrument switch-offs or decontaminations (marked by grey vertical bars in Fig. 4), have not been included in these averages.

Because of the sun-fixed ENVISAT orbit there is a oneto-one relationship between the latitude of the tangent point and time, as can be seen from the top parts of each sub-panel. Furthermore, also the tropopause height (calculated from collocated ECMWF data and shown as a black line in the lower part of the sub-figures) varies as function of time and 

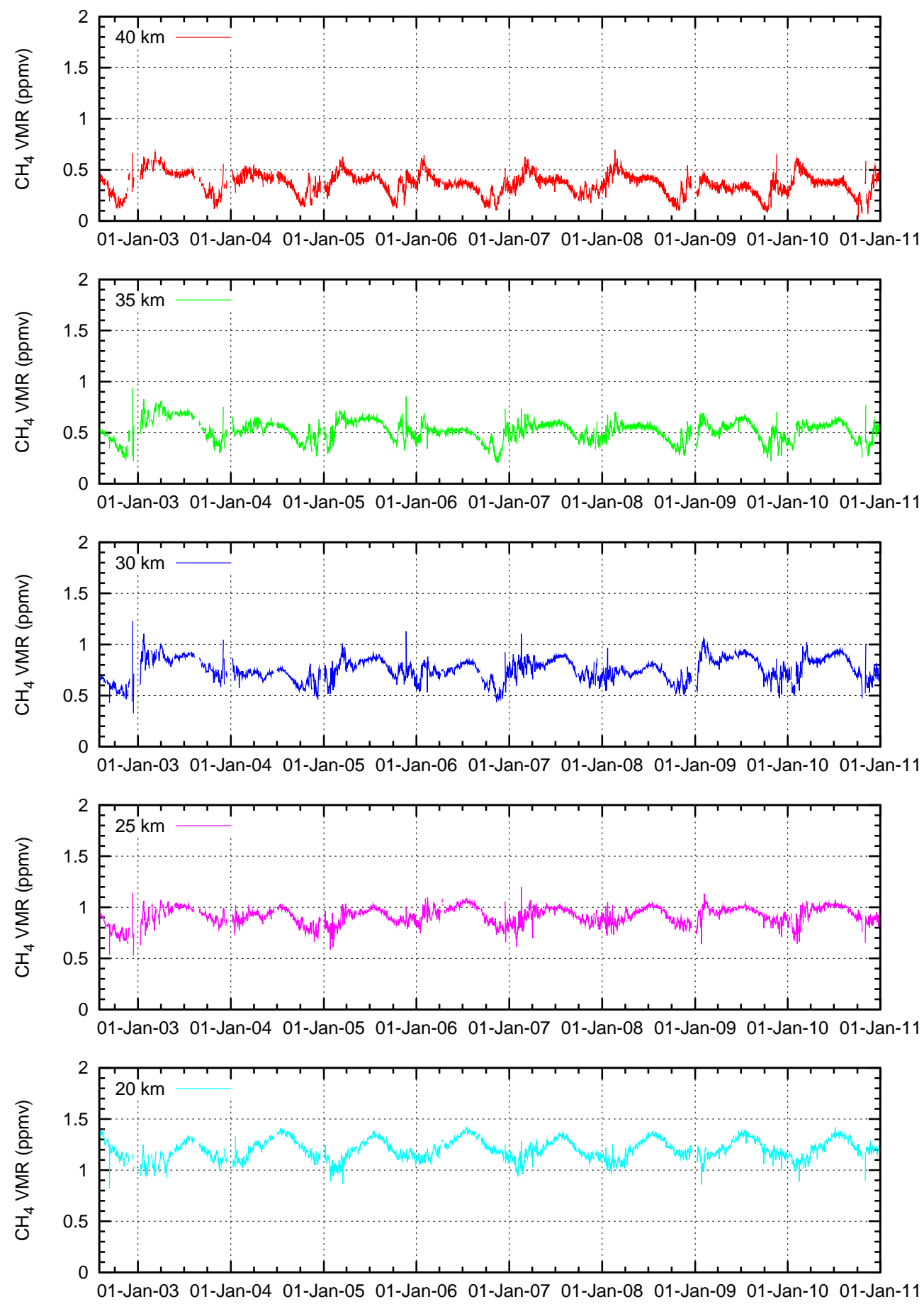

Fig. 5. Time series of SCIAMACHY $\mathrm{CH}_{4}$ VMRs (August 2002 to December 2010) at different altitudes based on daily average data.

latitude. This systematic coupling of observational time and space complicates the interpretation of the SCIAMACHY solar occultation time series.

The variation of the number densities and also VMRs with time seems rather smooth. There is a distinct seasonal variation visible in the $\mathrm{CH}_{4}$ time series. This variation occurs at all altitudes, but is most pronounced at lower altitudes with maximum VMRs occurring in summer (about $1.4 \mathrm{ppmv}$ at $20 \mathrm{~km}$ ) and minimum VMRs in winter (about $1.0 \mathrm{ppmv}$ at $20 \mathrm{~km}$ ), following roughly the variation of the tropopause height.

The shape of the seasonal signal in the $\mathrm{CH}_{4}$ time series varies with altitude, as can be seen from Fig. 5, showing 
series for 20, 25, 30, 35 and $40 \mathrm{~km}$ extracted from the daily average VMR data set given in Fig. 4b. Whereas the seasonal variation at lower altitudes have mainly a sinusoidal shape, very similar to the tropopause height variations, the time series at higher altitudes (where tropospheric influence is reduced) become more complex. Fig. 5 also shows that there is a significant day-to-day variation, especially in winter (and thus at high latitudes), which can not be that easily identified from the contour plots of Fig. 4. These short term variations are related to the occurrence of the polar vortex. $\mathrm{CH}_{4}$ concentrations inside the polar vortex are generally lower than outside the vortex, which is attributed to the downward transport of stratospheric air inside the vortex (see e.g. Nassar et al., 2005). In winter, the daily mean SCIAMACHY VMRs therefore depend strongly on the extent of the (usually asymmetric) polar vortex. Especially, on some days (e.g. 11 December 2002, 2 December 2003, 22 November 2005, 18 February 2007) sharp peaks are visible in the data. At these days only very few measurements were available (only 3-4 profiles), and these happen to be outside the vortex, which is why the average concentration is higher than the typical daily average in winter which usually contains data from both inside and outside the vortex.

\section{Conclusions}

First stratospheric $\mathrm{CH}_{4}$ profiles derived with an updated version of the Onion Peeling DOAS (ONPD) algorithm (current data product version 3.3.6) from SCIAMACHY solar occultation data look very promising. Reasonable results are obtained between 20 and $40 \mathrm{~km}$ altitude, but the mean errors of the SCIAMACHY $\mathrm{CH}_{4}$ product are still considerably high (10-20\% below $30 \mathrm{~km}$ and strongly increasing above). However, these errors are based solely on fit residuals and considered to be upper estimates. An extension of the retrieval to lower altitudes is desired but needs further investigation.

Comparisons of the SCIAMACHY $\mathrm{CH}_{4}$ profiles with ACE-FTS V2.2 data show a good correlation. SCIAMACHY and ACE-FTS VMRs agree typically within $10 \%$. This is in line with the expected accuracy of the ACE-FTS methane data.

Due to the observational geometry the SCIAMACHY $\mathrm{CH}_{4}$ profiles are restricted to a latitudinal range between about $50^{\circ} \mathrm{N}$ and $70^{\circ} \mathrm{N}$. Furthermore, there is a direct coupling between time and place of a measurement, which results in a pronounced seasonal cycle in the derived time series. This seasonal signal varies with altitude; tropospheric influence is visible at lower altitudes, i.e. the seasonality observed in the lower altitudes is mainly influenced by the seasonality of the tropopause height. Furthermore, there is an underlying shorttime variation which is especially strong in winter at higher latitudes, indicating an impact of the polar vortex.
Acknowledgements. SCIAMACHY is a national contribution to the ESA ENVISAT project, funded by Germany, The Netherlands, and Belgium. SCIAMACHY data have been provided by ESA. The Atmospheric Chemistry Experiment (ACE), also known as SCISAT, is a Canadian-led mission mainly supported by the Canadian Space Agency and the Natural Sciences and Engineering Research Council of Canada. We thank the European Centre for Medium Range Weather Forecasts (ECMWF) for providing us with analysed meteorological fields. We thank Geoffrey Toon of the NASA Jet Propulsion Laboratory for providing the empirical solar line list used in this work. This work has been funded by DLR Space Agency (Germany), the ESA GHG-cci and by the University of Bremen.

Edited by: J.-P. Pommereau

\section{References}

Bernath, P. F., McElroy, C. T., Abrams, M. C., Boone, C. D., Butler, M., Camy-Peyret, C., Carleer, M., Clerbaux, C., Coheur, P.-F., Colin, R., DeCola, P., DeMazière, M., Drummond, J. R., Dufour, D., Evans, W. F. J., Fast, H., Fussen, D., Gilbert, K., Jennings, D. E., Llewellyn, E. J., Lowe, R. P., Mahieu, E., McConnell, J. C., McHugh, M., McLeod, S. D., Michaud, R., Midwinter, C., Nassar, R., Nichitiu, F., Nowlan, C., Rinsland, C. P., Rochon, Y. J., Rowlands, N., Semeniuk, K., Simon, P., Skelton, R., Sloan, J. J., Soucy, M.-A., Strong, K., Tremblay, P., Turnbull, D., Walker, K. A., Walkty, I., Wardle, D. A., Wehrle, V., Zander, R., and Zou, J.: Atmospheric Chemistry Experiment (ACE): Mission overview, Geophys. Res. Lett., 32, L15S01, doi:10.1029/2005GL022386, 2005.

Bovensmann, H., Burrows, J. P., Buchwitz, M., Frerick, J., Noël, S., Rozanov, V. V., Chance, K. V., and Goede, A. H. P.: SCIAMACHY - Mission Objectives and Measurement Modes, J. Atmos. Sci., 56, 127-150, 1999.

Coldewey-Egbers, M., Weber, M., Lamsal, L. N., de Beek, R., Buchwitz, M., and Burrows, J. P.: Total ozone retrieval from GOME UV spectral data using the weighting function DOAS approach, Atmos. Chem. Phys., 5, 1015-1025, doi:10.5194/acp5-1015-2005, 2005.

De Mazière, M., Vigouroux, C., Bernath, P. F., Baron, P., Blumenstock, T., Boone, C., Brogniez, C., Catoire, V., Coffey, M., Duchatelet, P., Griffith, D., Hannigan, J., Kasai, Y., Kramer, I., Jones, N., Mahieu, E., Manney, G. L., Piccolo, C., Randall, C., Robert, C., Senten, C., Strong, K., Taylor, J., Tétard, C., Walker, K. A., and Wood, S.: Validation of ACE-FTS v2.2 methane profiles from the upper troposphere to the lower mesosphere, Atmos. Chem. Phys., 8, 2421-2435, doi:10.5194/acp-8-2421-2008, 2008.

Fischer, H., Birk, M., Blom, C., Carli, B., Carlotti, M., von Clarmann, T., Delbouille, L., Dudhia, A., Ehhalt, D., Endemann, M., Flaud, J. M., Gessner, R., Kleinert, A., Koopman, R., Langen, J., López-Puertas, M., Mosner, P., Nett, H., Oelhaf, H., Perron, G., Remedios, J., Ridolfi, M., Stiller, G., and Zander, R.: MIPAS: an instrument for atmospheric and climate research, Atmos. Chem. Phys., 8, 2151-2188, doi:10.5194/acp-8-2151-2008, 2008.

Gunson, M. R., Farmer, C. B., Norton, R. H., Zander, R., Rinsland, C. P., Shaw, J. H., and Gao, B.-C.: Measurements of $\mathrm{CH}_{4}, \mathrm{~N}_{2} \mathrm{O}$, $\mathrm{CO}, \mathrm{H}_{2} \mathrm{O}$, and $\mathrm{O}_{3}$ in the Middle Atmosphere by the Atmospheric 
Trace Molecule Spectroscopy Experiment on Spacelab 3, J. Geophys. Res., 95, 13867-13882, doi:10.1029/JD095iD09p13867, 1990.

Nassar, R., Bernath, P. F., Boone, C. D., Manney, G. L., McLeod, S. D., Rinsland, C. P., Skelton, R., and Walker, K. A.: ACE-FTS measurements across the edge of the winter 2004 Arctic vortex, Geophys. Res. Lett., 32, L15S05, doi:10.1029/2005GL022671, 2005.

Noël, S., Bovensmann, H., Burrows, J. P., Frerick, J., Chance, K. V., Goede, A. H. P., and Muller, C.: The SCIAMACHY Instrument on ENVISAT-1, in: Sensors, Systems, and NextGeneration Satellites II, edited by: Fujisada, H., vol. 3498 of Proc. SPIE 94-104, 1998.

Noël, S., Bramstedt, K., Rozanov, A., Bovensmann, H., and Burrows, J. P.: Water vapour profiles from SCIAMACHY solar occultation measurements derived with an onion peeling approach, Atmos. Meas. Tech., 3, 523-535, doi:10.5194/amt-3-523-2010, 2010.

Payan, S., Camy-Peyret, C., Oelhaf, H., Wetzel, G., Maucher, G., Keim, C., Pirre, M., Huret, N., Engel, A., Volk, M. C., Kuellmann, H., Kuttippurath, J., Cortesi, U., Bianchini, G., Mencaraglia, F., Raspollini, P., Redaelli, G., Vigouroux, C., De Mazière, M., Mikuteit, S., Blumenstock, T., Velazco, V., Notholt, J., Mahieu, E., Duchatelet, P., Smale, D., Wood, S., Jones, N., Piccolo, C., Payne, V., Bracher, A., Glatthor, N., Stiller, G., Grunow, K., Jeseck, P., Te, Y., and Butz, A.: Validation of version-4.61 methane and nitrous oxide observed by MIPAS, Atmos. Chem. Phys., 9, 413-442, doi:10.5194/acp-9-413-2009, 2009.

Remedios, J. J., Ruth, S. L., Rodgers, C. D., Taylor, R. W., Roche, A. E., Gille, J. C., Gunson, M. R., Russell, III, J. M., Park, J., Zipf, E. C., and Erdman, P. W.: Measurements of methane and nitrous oxide distributions by the improved stratospheric and mesospheric sounder: Retrieval and validation, J. Geophys. Res., 101, 9843-9871, 1996.
Roche, A. E., Kumer, J. B., Nightingale, R. W., Mergenthaler, J. L., Ely, G. A., Bailey, P. L., Massie, S. T., Gille, J. C., Edwards, D. P., Gunson, M. R., Abrams, M. C., Toon, G. C., Webster, C. R., Traub, W. A., Jucks, K. W., Johnson, D. G., Murcray, D. G., Murcray, F. H., Goldman, A., and Zipf, E. C.: Validation of $\mathrm{CH}_{4}$ and $\mathrm{N}_{2} \mathrm{O}$ measurements by the cryogenic limb array etalon spectrometer instrument on the Upper Atmosphere Research Satellite, J. Geophys. Res., 101, 9679-9710, doi:10.1029/95JD03442, 1996.

Rohs, S., Schiller, C., Riese, M., Engel, A., Schmidt, U., Wetter, T., Levin, I., Nakazawa, T., and Aoki, S.: Longterm changes of methane and hydrogen in the stratosphere in the period 1978-2003 and their impact on the abundance of stratospheric water vapor, J. Geophys. Res., 111, D14315, doi:10.1029/2005JD006877, 2006.

Rozanov, A., Rozanov, V., Buchwitz, M., Kokhanovsky, A., and Burrows, J. P.: SCIATRAN 2.0 - A new radiative transfer model for geophysical applications in the $175-2400 \mathrm{~nm}$ spectral region, Adv. Space Res., 36, 1015-1019, doi:10.1016/j.asr.2005.03.012, 2005.

Russell, III, J. M. and Drayson, S. R.: The Inference of Atmospheric Ozone Using Satellite Horizon Measurements in the $1042 \mathrm{~cm}^{-1}$ Band, J. Atmos. Sci., 29, 376-390, 1972.

Russell, III, J. M., Gordley, L. L., Park, J. H., Drayson, S. R., Hesketh, W. D., Cicerone, R. J., Tuck, A. F., Frederick, J. E., Harries, J. E., and Crutzen, P. J.: The Halogen Occultation Experiment, J. Geophys. Res., 98, 10777-10797, 1993.

Taylor, F. W., Rodgers, C. D., Whitney, J. G., Werrett, S. T., Barnett, J. J., Peskett, G. D., Venters, P., Ballard, J., Palmer, C. W. P., Knight, R. J., Morris, P., Nightingale, T., and Dudhia, A.: Remote Sensing of Atmospheric Structure and Composition by Pressure Modulator Radiometry From Space: The ISAMS Experiment on UARS, J. Geophys. Res., 98, 1079910814, doi:10.1029/92JD03029, 1993. 